\title{
Mediação Sanitária: diálogo e consenso possível
}

\author{
Sanitary Mediation: dialogue and possible consensus
}

Mediación Sanitaria: diálogo y consenso posible

RESUMO: O Direito à Saúde foi considerado um bem de relevância pública, a partir da Constituição de 1988. A população vive a dificuldade no acesso aos serviços e produtos para a saúde, estabelecendo-se um conflito entre o Estado e o usuário do sistema, com isso, recorre ao judiciário como possibilidade de acesso ao Sistema Único de Saúde. Nesse contexto, os meios consensuais para resolução de conflitos passam a ser considerados de forma mais efetiva, uma vez que o Poder Judiciário também não responde em tempo hábil à demanda do cidadão. Dois diplomas legais foram promulgados instituindo-se modos alternativos de resolução de conflitos, a Lei 13.105/2015 (Novo Código de Processo Civil) e a Lei 13.140/2015 (Lei da Mediação). Foi realizada uma revisão bibliográfica sobre esse novo instituto jurídico da Mediação. Para tanto foram consultados bancos de dados disponíveis na internet. Foram encontrados escassos trabalhos científicos sobre o tema, havendo maior prevalência na produção intelectual estrangeira. Conclui-se que a mediação e vertente sanitária passarão à obrigatoriedade judicial e extrajudicial no Brasil sem uma densa produção sobre o tema.

Palavras-chave: Mediação. Consenso. Conflito. Direito à Saúde.

ABSTRACT: The Legal Right to health was considered an issue of public significance, from the Constitution of 1988 . The population lives the difficulty in accessing services and health products, setting up a conflict between the State and the system user in spite of this, refers to the judiciary as a possibility of access the Health System. In this context, the consensual means of solving conflicts are now considered more effective, since the judiciary also does not respond in a timely manner the citizen's demands. Two legal instruments were enacted instituting alternative modes of conflict resolution. The Act 13.105 (Novo Código de Processo Civil) and the Act 13.140 (Lei da Mediação). A literature review on this legal institution of mediation was held. Therefore, was consulted database available on the internet. Were found few scientific papers on the subject, with a higher prevalence in foreign intellectual production. It concludes that mediation and its sanitary side will shed judicial and extrajudicial mandatory in Brazil without a dense literature on the subject

Keywords: Mediation, Consensus, Conflict, Legal right to health

RESUMEN: El derecho a la salud se considera un bien de importancia pública desde la Constitución de 1988. La población tiene dificultades para acceder a los servicios y

\footnotetext{
${ }^{1}$ Especialista em Auditoria de Saúde pela Universidade Gama Filho. Especialista em Saúde Pública pela UNESP. Bacharel em Direito. Bacharel em Enfermagem. Auditora de Sistema de Saúde. Advogada. Brasília - Distrito Federal. Brasil. E-mail: suzedantonio@gmail.com
} 
productos para la salud, creándose un conflicto entre el Estado y el usuario del sistema, con ello, recurre al poder judicial como una posibilidad de acceso al Sistema Único de Salud. En este contexto, los medios consensuales de resolución de conflictos se consideran actualmente más eficaces, ya que el poder judicial también no responde de manera oportuna a las demandas de los ciudadanos. Dos proyectos de ley se promulgaron instituyendo formas alternativas de resolución de conflictos, la Ley 13.105 (Nuevo Código de Proceso Civil) y la Ley 13.140 (Ley de Mediación). Se realizó una revisión bibliográfica sobre esta nueva institución jurídica de mediación. Por lo tanto, se consultaron las bases de datos disponibles en Internet. Se encontraron pocos artículos científicos sobre el tema, con una mayor prevalencia en la producción intelectual extranjera. Se llega a la conclusión de que la mediación y su perspectiva sanitaria llegarán a ser obligatorios tanto judicial como extrajudicialmente en Brasil sin una literatura densa sobre el tema.

Palabras-llave: Mediación. Consenso. Conflicto. Derecho a la Salud

\section{Introdução}

Os conflitos são intrínsecos a convivência humana e são oportunidades para se estabelecer o diálogo. Sendo fenômeno constitutivo da natureza humana, o conflito é caracterizado em duas correntes de pensamento: como fenômeno patológico e como fenômeno sociativo. É possível afirmar que 'a socialização humana se estrutura na relação dialética da cooperação e do conflito', Silva (1) entende que a cooperação de forma implícita 'pode ter suas bases em tensões e conflitos sutis'.

Há concepções para as quais o conflito é elemento negativo, anormal ou patológico, (2) (3). Outra corrente, o percebe enquanto relação social (4) ou como fator de interação social (5) e ainda para outras correntes, como fator de tensão e equilibrio de poderes nas configurações sociais (6).

Se o conflito é inerente à sociedade humana, é possível inferir que a busca por soluções factíveis, no campo teórico e da praxis também o é.

Embora a humanidade tenha se ocupado de jogos ao longo de sua história, ferramentas de análise e formalização dos processos que os envolvem são recentes. A teoria de jogos representa uma forma de dimensionar problemas que envolvem mais de um ator com capacidade para tomar decisões. Trata-se de utilizar estratégias de jogador como mecanismo de análise do conflito e tomada de decisão (7).

$\mathrm{Na}$ Teoria dos Jogos de Von Neumann são analisadas situações competitivas, com interesses conflitantes. A Teoria de Soma Zero trata de situações de tomada de decisão em que no mínimo dois oponentes podem ter finitas ou infinitas possibilidades ou 
estratégias para resolução racional do conflito, e a vitória de um é igual à derrota do outro, logo os dois jogadores somam zero. É um jogo essencialmente não cooperativo (7) (8).

Nesse contexto, em que se estudam as estratégias de tomadas de decisão entre jogadores, outra face da Teoria dos Jogos dá o tom da lógica ao entendimento de que é possível, em situação de conflito chegar a um resultado favorável às partes, de forma que todos ganhem.

$\mathrm{Na}$ Teoria do Equilíbrio de Nash, ou teoria dos jogos não competitivos são demonstradas situações em que nem sempre um jogador tenha que derrotar o outro para sair vitorioso, muitas vezes um depende do outro para obter o melhor resultado. Nesse ponto, complementa a teoria dos jogos competitivos, onde há no mínimo um perdedor e um ganhador (9).

A aplicação da Teoria dos Jogos é possível em diversas situações potencialmente conflituosas, incluindo políticas sociais e de saúde e conflitos entre grupos sociais (9). Situações semelhantes são vivenciadas por indivíduos e coletividades que buscam acesso a justiça. O clássico dilema do prisioneiro ${ }^{2}$ mostra a dificuldade que se tem para manter a cooperação em situações de tensão. Na incessante busca por justiça social, a teoria dos jogos não competitivos aponta para um caminho possível, o da solução mediante consenso.

Não se pode olvidar que todas as multifacetadas e fragmentadas relações sociais experimentam conflitos em determinado momento, sendo esta conflitualidade um traço contemporâneo que se expande nas esferas local e mundial, do mesmo modo que falar em conflito social se tornou um inevitável lugar-comum, especialmente quando se verifica que a "sólida" resposta que se espera por parte do Judiciário, esmaeceu corroída pela incapacidade de dar conta de tamanha complexidade que perpassa as relações sociais e estratégias hegemônicas atuais. (11)

Apesar da expressão 'acesso a Justiça' ser de difícil definição, serve para determinar duas finalidades básicas do sistema jurídico, aquela pela qual as pessoas podem reivindicar seus direitos e resolver seus litígios mediante prestação jurisdicional

\footnotetext{
2 Dilema dos prisioneiros. É um jogo que representa bem o dilema entre cooperar e trair. Dois suspeitos, Ae B, são presos pela polícia. A polícia não tem provas suficientes para condená-los, então separa os prisioneiros em salas diferentes e oferece a ambos o mesmo acordo: 1. Se um dos prisioneiros confessar (trair o outro) e o outro permanecer em silêncio, o que confessou sai livre enquanto o cúmplice silencioso cumpre 10 anos. 2. Se ambos ficarem em silêncio (colaborarem um com ou outro), a polícia só pode condená-los a um ano cada um. 3. Se ambos confessarem (traírem o comparsa), cada um leva cinco anos de cadeia (10).
} 
do Estado, e a que pressupõe o acesso à justiça social (12). Na esteira da segunda finalidade encontra-se o objeto da mediação sanitária.

Segundo Cappelletti (12), o acesso à justiça determina uma das finalidades básicas do sistema jurídico, produzir resultados que sejam individual e socialmente justos.

Para entender como se dá esse processo de resolução de conflito e construção de consenso, são apresentados elementos que permitem navegar nos prismas que envolvem a disputa, a mediação e o consenso possível.

Ao pensar em mediação, a correlação com linguagem, diálogo e interação social é praticamente inevitável. Na teoria do agir comunicativo, Habermas (13) parte do princípio de que é por meio da linguagem que os homens se constituem em sujeitos de ação e estabelecem um contexto de relações e interações sociais que desencadeiam os processos de mudança (14).

A técnica da mediação não é recente, e "há muito tempo é utilizada em várias culturas no mundo, como a judaica, a cristã, a islâmica, a hinduísta, a budista, a confucionista e até as indígenas" (15).

A mediação é definida como o mecanismo pelo qual um terceiro tenta que as partes discutam o conflito para que construa entre elas a solução da disputa (16), podendo se dar no âmbito judicial ou extrajudicial, como meio alternativo de solução de conflitos, juntamente com a arbitragem, a negociação e a conciliação.

A mediação também é compreendida como "um processo em que um terceiro desinteressado (ou parte neutra) ajuda os contendores na consecução de um acerto voluntário quanto a suas diferenças por meio de um acordo [...]" (17).

Para Cebola (16) a mediação pode ser definida como:

Método de resolución de conflitos em que um professional - el mediador - percibiendo los objetivos de las partes e los obstáculos y recursos disponibles, emplea técnicas e instrumentos para fomentar el diálogo entre los sujetos em disputa, em ordem a que construjan alternativas de solución (devendo recoger la que mejor responda a los interesses de ambos). (15) ${ }^{3}$

\footnotetext{
${ }^{3}$ Método de resolução de conflitos em que um profissional - o mediador - percebendo os objetivos das partes e os obstáculos e recursos disponíveis emprega técnicas e instrumentos para promover o diálogo entre os sujeitos em litígio, de forma que cons truam alternativas de solução (devendo escolher a que melhor responda aos interesses de ambos). (tradução livre da autora).
} 
A Lei 13.140/2015, Lei da Mediação (18) trabalhou com conceitos atuais, adaptados à realidade brasileira, em que "mediação é um processo decisório conduzido por terceiro imparcial, com o objetivo de auxiliar as partes a identificar ou desenvolver soluções consensuais" (19). A mediação "não pode ser imposta jamais, bem como a recusa em participar do procedimento não deve acarretar qualquer sanção a nenhuma das partes [...]" (19).

No Brasil, a prática da autocomposição como alternativa para a resolução de conflitos começou a ganhar forma no Código de Processo Civil (1973) (20), quanto ao procedimento sumaríssimo, com a previsão de audiências de conciliação e, igualmente, a partir da instituição dos juizados especiais civis e criminais, com a Lei dos Juizados Lei 9.099 de 1995 (21) - prevendo também a transação no âmbito penal. A Justiça do Trabalho já tem essa previsão na Consolidação das Leis do Trabalho - CLT (22), desde 1943.

Com sua cultura positivista, o Brasil trata como imprescindível a normatização legal da mediação, o que ocorreu com o Novo Código de Processo Civil - NCPC (23). Este instituto traz para o direito brasileiro o princípio da cooperação, traduzido em "instrumentos que incentivam o diálogo e a colaboração das partes entre si e delas com o juiz [...]" (24).

No Brasil, a cultura prevalente é a adversarial e a inquisitiva, que deve ser superada, porque

A experiência tratou de demonstrar que a resolução de conflitos pela via da jurisdição contenciosa, com o Estado-juiz dando uma solução para a lide que muitas vezes não agrada a nenhuma das partes e demora excessivamente para chegar, gera gastos e transtornos excessivos para os indivíduos (24).

Não há divergência quanto à afirmação de que a mediação seja uma ação dialogada, e através da linguagem, do diálogo, os homens se constituem em sujeitos de ação, e no contexto das relações e interações sociais desencadeiam processos de mudança pelo debate e busca do consenso.

Essa característica se aplica a qualquer forma de mediação, inclusive a mediação sanitária, "um modelo alternativo de resolução de conflitos na área da saúde" (25), objeto desse estudo. 
O escopo deste trabalho foi reunir as diferentes visões da literatura acadêmica atual e legislação vigente sobre mediação e mediação sanitária, com o objetivo de compreender o novo instituto.

\section{Metodologia}

Foi realizada uma revisão bibliográfica nas bases de dados scielo; google acadêmico; Periódicos Capes e no acervo da Biblioteca Luiz Vianna Filho, em que foram consultados livros, artigos e periódicos.

Os descritores utilizados foram: Mediação, Consenso, Conflito e Direito à Saúde.

Foram considerados todos os textos e manuscritos encontrados, além de todas as regras jurídicas que responderam ao critério da investigação. Esses dados formaram o universo da pesquisa.

Para a busca de informações legislativas pesquisou-se o banco de dados do Planalto, disponível na internet, o sitio do Conselho Nacional de Justiça e o Google, igualmente disponível na web, utilizando o descritor mediação. Em razão do ineditismo do tema e da produção ainda esparsa, houve a opção pela não delimitação temporal.

\section{Resultados e discussões}

Foram encontradas 4 normas jurídicas sobre o tema da mediação e conciliação, sendo 2 infralegais. $E$ no que se refere à pesquisa bibliográfica, com o termo mediação sanitária, foram encontrados 8 artigos.

A Resolução n. 125, de 2010 (26), do Conselho Nacional de Justiça - CNJ analisa o direito de acesso à justiça previsto no art. 5ํ, inciso XXXV da Constituição Federal (27), além de considerar o formal ingresso aos órgãos judiciários, também diz respeito ao acesso à ordem jurídica justa. Na referida resolução o CNJ institui a Política Judiciária Nacional de tratamento dos conflitos de interesse, "tendente a assegurar a todos o direito à solução dos conflitos por meios adequados à sua natureza e peculiaridade" (26).

A depender do tipo e da natureza do conflito será necessário proporcionar a solução mais apropriada. O que muitas vezes não será uma ação judicial, mas a oportunidade de mediar e/ou conciliar. Aos órgãos judiciários, portanto, cabe 
desenvolver "mecanismos de solução de controvérsias, em especial os chamados meios consensuais como a mediação e a conciliação [...]" (26).

No Código de Ética do Advogado, no seu art.2ํㅗ § único, VI, expressamente figura dentre os deveres do profissional, "estimular a conciliação entre os litigantes, prevendo, sempre que possível, a instauração de litígios" (28).

A evolução do tratamento legislativo dado à mediação no ordenamento jurídico brasileiro coaduna na promulgação do Novo Código de Processo Civil e da Lei de Mediação, ambos aqui interpretados sob a perspectiva sanitária.

No Novo Código de Processo Civil - NCPC, Lei 13.105/2015 os institutos da conciliação e da mediação são tratados especialmente nos artigos 165 a 175. Cuida-se principalmente da atividade de mediação judicial (23).

Esse instituto altera o procedimento ordinário, introduzindo audiência de mediação ou conciliação entre a inicial (manifestação do autor) e a contestação (manifestação do réu) em ações judiciais. Com isso, existe a pretensão de conduzir as partes para a solução consensual do conflito, para só após, frustrada a pretensão, dar seguimento à ação. Todavia, segundo esse dispositivo, mediante manifestação de ambas as partes, de forma expressa, sobre o desinteresse na composição consensual, essa audiência não será realizada (art.334 §§ $4^{\circ}$ e $5^{\circ}$ ). O que permite inferir que a audiência de mediação ou conciliação passa a ser obrigatória para o acesso ao judiciário. Nesse ponto resta mitigado o princípio da autonomia das partes (23).

A norma disposta no art. 174 do NCPC (23) traz a disposição para que os entes federados criem as câmaras de mediação e conciliação relacionadas à solução de conflitos no âmbito administrativo.

A Lei de Mediação (18) que entrou em vigor em dezembro de 2015, dispõe sobre a mediação como meio de solução de controvérsias entre particulares e sobre a autocomposição de conflitos no âmbito da administração pública. Também dispõe que a mediação será pautada pela autonomia da vontade das partes - art. $2^{\circ}, \mathrm{V}$ e art. $7^{\circ}$. Entretanto, esse princípio só se aplica integralmente à mediação extrajudicial.

Algumas diferenças básicas entre o instituto da mediação e da conciliação permitem que se eleja entre um ou outro instituto à luz da natureza do caso concreto, e mesmo da relação existente entre as partes litigantes. 
A conciliação é uma forma de resolução de conflitos administrada por um conciliador, terceiro imparcial, com prerrogativa para sugerir e formular propostas e apontar vantagens e desvantagens para a tomada de decisão das partes (29). $\mathrm{Na}$ mediação, não pode o mediador fazer parte do procedimento dialogado opinando acerca de qual seria a melhor solução para a controvérsia, "seu papel se restringe ao auxílio da comunicação entre as partes, para que possam juntas encontrar a solução adequada para o problema em questão [...]" (30).

Na mesma linha, "o conciliador pode sugerir soluções para o litígio, ao passo que o mediador auxilia as pessoas em conflito a identificarem, por si mesmas alternativas de benefício mútuo" (24).

Ao utilizar a mediação como método para resolução de conflito "permite o desenvolvimento do protagonismo, ou seja, fortalece a capacidade de as pessoas analisarem situações e tomarem decisões efetivas sobre si mesmas" (31).

São três elementos básicos no processo de mediação: a existência de partes em conflito, uma clara contraposição de interesses e, uma terceira pessoa neutra e capacitada a facilitar a busca pelo acordo (31).

Há autores que defendem que o mecanismo da mediação não poderá ser utilizado para todo e qualquer conflito, sua razão de ser está nos conflitos surgidos a partir de relações duradouras, ou seja, que preexistem à lide e que continuarão a existir, independente da solução dada àquele caso (29).

A mediação pode ser entendida como método integrado no sistema de resolução de conflitos jurídicos, de um dado ordenamento, e, sob a égide de princípios éticos e deontológicos, deve ajudar as partes na construção da solução através do diálogo e acordo mútuo (16).

$\mathrm{Na}$ literatura consultada foi observada divergência quanto à mediação ser considerada alternativa de resolução de controvérsia da espécie autocomposição ou heterocomposição. Alguns autores (32) consideram a mediação como espécie de heterocomposição pelo simples fato de contar com um terceiro, ainda que este não interfira no procedimento. Por esse entendimento, apenas a negociação seria espécie de autocomposição. Outros entendem que o mediador não integra o litígio e, embora 
possa até sugerir alguma solução para o conflito, a decisão em aceitá-la, e efetivar algum acordo é das partes mediadas, o que configura autocomposição.

O NCPC (23) considera mediação e conciliação como método autocompositivo. Explicitamente está disposto no art. 139, inciso $\mathrm{V}$, que o juiz promoverá a qualquer tempo a autocomposição com o auxílio de conciliadores e mediadores judiciais (23).

É possível concluir que a mediação não compõe a heterocomposição, porque nessa espécie se impõe às partes uma decisão, tal qual ocorre na arbitragem e no sistema jurisdicional clássico. A despeito disso, o termo heterocomposição em sentido lato é empregado para qualquer sistema com intervenção de um terceiro na solução do conflito (32).

$\mathrm{Na}$ conciliação, o terceiro se limitará a aproximar as proposições das partes, enquanto na mediação o papel do terceiro - mediador - além de promover o diálogo entre as partes, deve propor uma solução para elas. Apesar de que, na literatura jurídica não há unanimidade quanto à terminologia utilizada (32).

Quando o conflito a ser mediado é relativo ao tema saúde, se está diante do procedimento de mediação sanitária.

A resolução extrajudicial de conflitos sanitários é realidade em diversos países e tem sido estudado no direito comparado, muito embora no Brasil ainda seja tímida a produção acadêmica sobre o assunto, em que pese a crescente demanda judicial advinda de usuários do sistema de saúde brasileiro, público ou privado.

Em países europeus como França, Hungria e Suécia, e ainda, países latinoamericanos como México, Chile e Argentina as experiências são mais amplas no campo da resolução de conflitos sanitários extrajudiciais (32).

Ainda no campo do direito comparado, tem sido trazido às discussões sistemas extrajudiciais de responsabilidade sem culpa - responsabilidade objetiva. No Brasil, pode-se dizer da responsabilidade do Estado na prestação do serviço público de saúde.

No âmbito sanitário, o termo 'mediação' vem se atando à capacidade do mediador de propor soluções, inclusive de forma expressa. As soluções trazidas pelo mediador são construídas mediante elementos trazidos pelas partes durante procedimento dialogado (32). 
Em ensaio de sistematização de tipos de conflitos sanitários susceptíveis de resolução na forma extrajudicial (32) são elencados os seguintes

a) conflitos por defeito na prestação do serviço de saúde, entre o paciente e o prestador do serviço; b) conflitos em matéria de plano de saúde, entre a seguradora e o segurado ou beneficiário e c) conflitos em matéria de publicidade sanitária, entre o anunciante e o prejudicado (32).

Embora obviamente não se trate de lista exaustiva, para a realidade brasileira, acrescentar-se-ão conflitos entre o Sistema Único de Saúde, por gestores de cada ente federado e o usuário do sistema, quanto ao acesso a serviços e produtos para a saúde.

No contexto social atual não se admite conceber saúde isoladamente, seu conceito cada vez mais abrangente impende para a intersetorialidade, eixo estruturador das políticas públicas, o que possibilita uma abordagem geral dos problemas sociais. Nesse diapasão, pensar saúde compreende também a interdisciplinaridade, com múltiplos mecanismos, instituições e políticas entrelaçadas e em permanente diálogo para tornar realidade as mudanças que gradativamente vem sendo construídas.

As políticas econômicas influenciam, e até determinam a implantação das demais políticas, principalmente as políticas: de saúde, educação, ambiente, habitação, transporte, segurança, lazer, alimentação e assistência social, dentre outras. Por sua vez, estas se impactam mutuamente e são determinantes do nível de saúde individual e coletivo.

Com a promulgação da Constituição Cidadã, em 1988 (27), a saúde foi reconhecida como um direito social, um bem a ser protegido e garantido de forma integral e universal pelo Estado. A partir de então, "os cidadãos brasileiros passaram a ter a prerrogativa de reivindicarem este direito em juízo, acionando legitimamente o Estado para a garantia de suas pretensões sanitárias" (33).

$\mathrm{O}$ conflito entre as necessidades individuais e coletivas, que permeia a garantia de um direito complexo como o direito à saúde, vem mostrando que os sistemas político, jurídico e médico-sanitário precisam avançar, conjuntamente, para responderem às demandas de saúde. (33).

Em que pese a garantia constitucional do direito à saúde a todas as pessoas em solo brasileiro, a consolidação do SUS tem ocorrido de forma lenta e gradativa. Essa lentidão interfere na implementação das políicas de saúde, determinando a ineficiência 
e ineficácia do Sistema. Enquanto isso a população vê no judiciário uma porta de acesso ao Sistema de Saúde, levando ao que se convencionou chamar 'fenômeno da judicialização'.

Para os conflitos na área da saúde, a Mediação se mostra muito eficaz, pois é uma ADR de caráter voluntário no qual um terceiro, o mediador, de forma neutra, imparcial e confidencial, guia as partes para que essas alcancem um acordo, sem que o mesmo decida a situação conflitiva. (35).

A prática da mediação sanitária, uma ADR - Alternative Dispute Resolution (sistema alternativo de resolução de conflitos) tem se mostrado eficaz como alternativa à judicialização da saúde, descrições de experiências e estudos temáticos apontam para essa assertiva. Contudo, os relatos de mediação nos conflitos sanitários no Estado brasileiro reportam para uma prática não sistematizada (36).

Com a regulamentação legal da mediação, é provável que se caminhe para a sistematização do procedimento também no âmbito sanitário, embora exista uma liberdade para sua adequação ao tipo de conflito, às partes envolvidas e aos recursos disponíveis.

Os entes federados, bem como seus órgãos e autarquias, poderão criar câmaras de prevenção e resolução de conflitos administrativos. Também poderão instaurar procedimento de mediação coletiva de conflitos relacionados à prestação de serviços públicos (23).

A mediação não abarca todo e qualquer tipo de conflito, e a mediação sanitária da mesma forma, responde a dados conflitos como aqueles ocorridos entre médico e pacientes, o 'SUS' e seus usuários e os entes federados (municípios, estados e união) entre si.

Ainda há escassez de publicações referentes ao tema mediação (lato sensu) no âmbito nacional, e especialmente sobre mediação sanitária apenas duas publicações foram encontradas.

\section{Conclusão}

A ideia de um pleno acesso à justiça continua sendo um desejo coletivo. Com o entendimento dos cidadãos de pertencer a uma sociedade de direito, o modelo 
hegemônico de instituições públicas passa a ser questionadas e já não respondem às demandas sociais.

A mediação não é uma prática recente, entretanto, no Brasil passa a ser considerada como possibilidade de apaziguar a sociedade num contexto de crise do Judiciário que considera apenas o modelo adversarial e inquisitivo.

Com o novo CPC a mediação e a conciliação são normatizadas e incentivadas para os casos em que há pressupostos para sua utilização. A Lei da Mediação cumpre o papel de elo entre o CPC e a Resolução 125 do CNJ. Ambos os institutos convergem no entendimento de que as partes têm autonomia para aceitação das regras procedimentais e a elas cabe decidir sobre o resultado, que pode ser com acordo, sem acordo, ou parcialmente acordado.

Os autores consultados trazem entendimento distinto sobre o nível de interferência do mediador no processo de mediação. Para o mediador sanitário, mediante análise dos elementos trazidos de forma dialogada, é admitido que ao identificar possíveis soluções, as submeta ao crivo das partes.

A Mediação pode ser aplicada em casos onde as partes sejam compostas por entes públicos, ou entre o público e o privado e admite flexibilidade em sua forma, o que torna não só possível, mas indicado como método para a resolução de conflitos no âmbito das questões sanitárias, incluindo aquelas oriundas do Sistema Único de Saúde.

A temática da mediação tem grande relevância para o tratamento dos conflitos e litígios ocorridos no setor da saúde, por isso é necessário que a comunidade científica empenhe forte investimento na exploração do tema, dada a carência da atual produção acadêmica.

\section{Referências}

1. Silva MJD. O conflito social e suas mutações na teoria sociológica. Qualit@s Revista Eletrônica. 2011, 12 (2): 1-12. Disponível em:

http://revista.uepb.edu.br/index.php/qualitas/. [Acesso em 23 out 2015]

2. Marx K, Ranieri J. Manuscritos econômico-filosóficos. São Paulo: Boitempo Editorial, 2004.

3. Durkhim É. Da divisão do trabalho social. São Paulo: Martins Fontes; 1995. 
4. Weber M. Economia e Sociedade. 3.ed. Brasília: Editora UnB; v.1. 1994.

5. Slimmel G. Sociología: Estudios sobre las formas de socializacíon. Madri: Alianza Editorial;1986

6. Elias N. Introdução à Sociologia. Lisboa: Editora 70; 2008

7. Fiani R. Teoria dos Jogos. Rio de Janeiro: Elsevier; 2009.

8. Neumann JV, Morgenstern O. Theory of Games and Economy Behavior. USA:

Princeton University Press; 2007.

9. Nash J. Two-person cooperative games: Econometrica,128-140. 1953. Disponível em:

http://users.auth.gr/users/7/8/007287/public_htm//Research/GameTheory/05PapersAdva nced/PapersByNash/Nash1953.pdf. [Acesso em 19 nov 2015].

10. Junior GBV. Teoria dos jogos. Disponível em http://www.cpaqv.org/epistemologia/teoriadosjogos.pdf. [Acesso em 31 out 2015].

11. Lucas DC, Spengler FM. Justiça restaurativa e mediação: políticas públicas no tratamento dos conflitos sociais. ljuí: Unijuí, 2011.

12. Cappelletti M, Garth B. Acesso a Justiça. Porto Alegre: Sergio Antonio Fabris, 2002.

13. Habermas, J. Teoría de la acción comunicativa. Volumen 1: Racionalidad de la acción y racionalización social. Madrid: Taurus, 1987.

14. Garrido LV. Habermas y la teoria de la acción comunicativa: Razón y Palabra. Revista eletrônica. Disponível em: http:/www.razonypalabra.org.mx/N/N75/ultimas/38_ Garrido_M75.pdf. [Acesso em 16 set 2015].

15. Moore CW. O processo de mediação: estratégias práticas para a resolução de conflitos. Porto Alegre: Artmed, 1998, p.32.

16. Cebola CM. La mediación: un nuevo instrumento de la administración de la justicia para la solución de conflictos [Tese]. Madrid: Departamento de Derecho Administrativo, Financiero Y Procesal, Universidad de Salamanca; 2011. Disponível em:

http://gredos.usal.es/jspui/bitstream/10366/110503/1/DDAFP_Marques_Cebola_C_La Mediacion.pdf. [Acesso em 10 ago 2015].

17. Cooley JW, Loncan R [tradução]. A advocacia na mediação. 2. ed. Brasilia: Editora Universidade de Brasília, 2001, p.24.

18. Brasil. Lei 13.140, de 26 de junho de 2015. Brasília. Dispõe sobre a mediação entre particulares como meio de solução de controvérsias e sobre a autocomposição de 
conflitos no âmbito da administração pública. Disponível em:

http://www.planalto.gov.br/ccivil_03/_Ato2015-2018/2015/Lei/L13140.htm. [Acesso em 29 set 2015].

19. Pinho HDB. A mediação e o código de processo civil projetado. 2012. Disponível em: https://www.academia.edu/4246510/A MEDIACAO E O CPC PROJETADO 280612. [Acesso em 23 out 2015].

20. Brasil. Lei 5.869, de 11 de janeiro de 1973. Brasília. Código de Processo Civil. Disponível em: http://www.planalto.gov.br/ccivil 03/leis/L5869compilada.htm. [Acesso em 19 nov 2015].

21. Brasil. Lei 9.099 , de 26 de setembro de 1995. Brasília. Dispõe sobre os Juizados Especiais Cíveis e Criminais e dá outras providências. Disponível em: http://www.planalto.gov.br/ccivil_03/LEIS/L9099.htm. [Acesso em 23 out 2015].

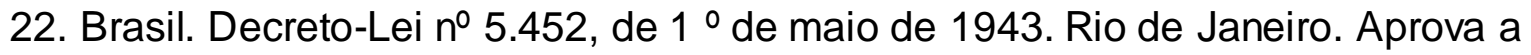
Consolidação das Leis do Trabalho. Disponível em: http://www.planalto.gov.br/ccivil_03/decreto-lei/Del5452.htm. [Acesso em 23 out 2015].

23. Brasil. Lei 13.105 , de 16 de março de 2015. Novo Código de Processo Civil. Rio de Janeiro: Forense; 2015.

24. Pinho HDB, Alves TM. Novos desafios da mediação judicial no Brasil: a preservação das garantias constitucionais e a implementação da advocacia colaborativa. Revista de informação legislativa. 2015, 52 (205): 55-70. Disponível em:

http://www2.senado.gov.br/bdsf/item/id/509924. [Acesso em 23 out 2015].

25. Delduque MC, Castro EV. A Mediação Sanitária como alternativa viável à judicialização das políticas de saúde no Brasil: Saúde Debate. 2015, 39 (105): 506-513. Disponível em:

https://scholar.google.com.br/scholar?q=media\%C3\%A7\%C3\%A3o+judicializa\%C3\%A7 $\%$ C3\%A3o\&btnG=\&hl=pt-BR\&as_sdt=0\%2C5

[Acesso em 04 set 2015].

26. Brasil. Conselho Nacional de Justiça. Resolução no 125 de 29 de novembro de 2010. Dispõe sobre a Política Judiciária Nacional de tratamento adequado dos conflitos de interesses no âmbito do Poder Judiciário e dá outras providências. Diário da Justiça (2010, dez, 01). Disponível em: http://www.cni.jus.br/busca-atos-adm?documento=2579. [Acesso em 30 jul 2015].

27. Brasil. Constituição da República Federativa do Brasil, 8 de outubro de 1988.

Brasília: Senado Federal.

28.Código de Ética dos Advogados do Brasil, 1995. Disponível em http://www.oab.org.br/arquivos/pdf/LegislacaoOab/codigodeetica.pdf. [Acesso em 22 set 2015]. 
29. Pinho HDB. Teoria geral da mediação à luz do Projeto de Lei e do direito comparado. Rio de Janeiro: Lumen Juris; 2008.

30. Sales LMM, Rabelo CMS. Meios consensuais de resolução de conflitos:

Instrumentos de democracia. Revista de Informação Legislativa 46 (105): 75-88,2015. Disponível em: http://www2.senado.leg.br/bdsf/item/id/194916. [Acesso em 23 out 2015].

31. Pinho HDB. O novo CPC e a mediação: reflexões e ponderações. Revista de informação legislativa; 201148 (190): 219-235. Disponível em: http://www2.senado.leg.br/bdsf/item/id/242895. [Acesso em 23 out 2015].

32. Cayón JC. Resolución Extrajudicial de Conflictos Sanitarios: Manifestaciones Jurídico-Positivas y Posibilidades de Futuro. In: Villuenga LG, Urbina JT, Castro EV, codirectores. Mediación, arbitraje y resolución extrajudiaial de conflitos em el siglo XXI: Arbitraje y resolución extrajudicial de conflitos. Madri: Reus S.A.; 2010: 293-329.

33. Alves SMC, Delduque MC, Neto ND, organizadores. Direito Sanitário em Perspectiva. 2 ed. Brasília: Fiocruz; 2013. Delduque MC, Marques SB, Ciarlini A. Judicialização das Políticas de Saúde no Brasil, 181-217.

34. Delduque MC, Cayón JC. A Mediação como alternativa à Judicialização da Saúde. Blog Direito Sanitário: Saúde e Cidadania. Disponível em

http://blogs.bvsalud.org/ds/2013/07/08/a-mediacao-como-alternativa-a-judicializacao-dasaude/. [Acesso em 10 nov 2015].

36. CONASS. Para Entender a Gestão do SUS. Direito à Saúde. Organização das SES para enfrentar a Judicialização - Experiências. Conselho Nacional de Secretários de Saúde - Brasília: CONASS, 2015: 85-95.

Recebido em 30/1/2016

Aprovado em 8/4/2016

Como citar este artigo:

D’Antonio SS. Mediação Sanitária: diálogo e consenso possível. Revista Cadernos Ibero-Americanos de Direito Sanitário. 2016 abr./jun, 5(2):8-22. 